\title{
INFRASOUND STUDIES FOR YIELD ESTIMATION OF HE EXPLOSIONS
}

Paul Golden, et al.

Southern Methodist University

3225 Daniel St.

Dallas, TX 75275

5 - XQH2012

Final Report

APPROVED FOR PUBLIC RELEASE; DISTRIBUTION IS UNLIMITED.

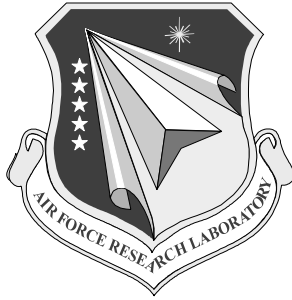

AIR FORCE RESEARCH LABORATORY

Space Vehicles Directorate

3550 Aberdeen Ave SE

AIR FORCE MATERIEL COMMAND

KIRTLAND AIR FORCE BASE, NM 87117-5776 


\section{DTIC COPY}

\section{NOTICE AND SIGNATURE PAGE}

Using Government drawings, specifications, or other data included in this document for any purpose other than Government procurement does not in any way obligate the U.S. Government. The fact that the Government formulated or supplied the drawings, specifications, or other data does not license the holder or any other person or corporation; or convey any rights or permission to manufacture, use, or sell any patented invention that may relate to them.

This report was cleared for public release by the Air Force Research Laboratory 377 ABW Public Affairs Office and is available to the general public, including foreign nationals. Copies may be obtained from the Defense Technical Information Center (DTIC) (http://www.dtic.mil).

AFRL-RVIPS-TR-2012-0084 HAS BEEN REVIEWED AND IS APPROVED FOR PUBLICATION IN ACCORDANCE WITH ASSIGNED DISTRIBUTION STATEMENT.

//signed// / / / / nigned//

Robert J. Raistrick

Program Manager, RVBYE

Joel B. Mozer

Chief, AFRL/RVB

This report is published in the interest of scientific and technical information exchange, and its publication does not constitute the Government's approval or disapproval of its ideas or findings. 


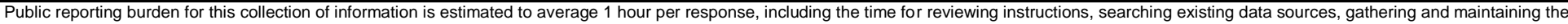

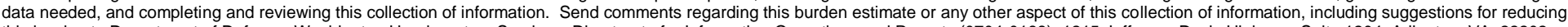

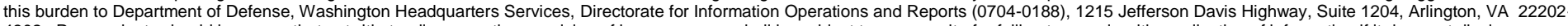

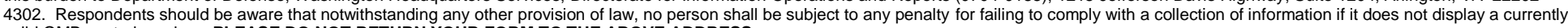
valid OMB control number. PLEASE DO NOT RETURN YOUR FORM TO THE ABOVE ADDRESS.

1. REPORT DATE $(D D-M M-Y Y Y Y) \quad$ 2. REPORT TYPE $\quad$ 3. DATES COVERED $(F r o m$ - To $)$

\begin{tabular}{l|l}
$05-0]-2012$ & Final Report \\
\hline
\end{tabular}

4. TITLE AND SUBTITLE

05 Mar 2010 to 05 Mar 2012

Infrasound Studies for Yield Estimation of HE Explosions

5a. CONTRACT NUMBER

FA9453-10-C-0212

6. AUTHOR(S)

5b. GRANT NUMBER

5c. PROGRAM ELEMENT NUMBER

$62601 \mathrm{~F}$

5d. PROJECT NUMBER

1010

Paul Golden, Petru Negraru, and Jesse Howard

5e. TASK NUMBER

PPM00000924

5f. WORK UNIT NUMBER

EF004019

7. PERFORMING ORGANIZATION NAME(S) AND ADDRESS(ES)

8. PERFORMING ORGANIZATION REPORT

Southern Methodist University

NUMBER

3225 Daniel St.

Dallas, TX 75275

\section{SPONSORING / MONITORING AGENCY NAME(S) AND ADDRESS(ES)}

Air Force Research Laboratory

Space Vehicles Directorate

3550 Aberdeen Ave SE

Kirtland AFB, NM 87117-5776
10. SPONSOR/MONITOR'S ACRONYM(S)

AFRL/RVBYE

11. SPONSOR/MONITOR'S REPORT

NUMBER(S)

AFRL-RV-PS-TR-2012-0084

\section{DISTRIBUTION / AVAILABILITY STATEMENT}

Approved for public release; distribution is unlimited. (377ABW-2012-0472 dtd 18 Apr 2012)

\section{SUPPLEMENTARY NOTES}

\section{ABSTRACT}

In this report we discuss the capability of estimating the yield of an explosion from infrasound signals generated by low yield chemical explosions. We used several datasets acquired at distances ranging from near source to the limit of the so called Zone of Silence (300 km). In general, the yield of the explosion is estimated either from the peak amplitude or from the dominant period of the observed signal. Near source observations show that the best way to estimate the yield of explosion is from an integral of the actual overpressure pulse. This method was proven to be superior to either period or peak amplitude. A small dataset of observations at 14 distances, ranging from 20 to $176 \mathrm{~km}$, shows that when similar propagation mechanisms are involved the amplitudes decay in the same way. There is however about one order of magnitude difference among the amplitudes of those arrivals, which current wind corrections fail to explain. A large dataset of observations at fixed distances shows that ranges of yield estimates are about one order magnitude for period based methods and larger for amplitude based methods. The key to improving the estimates may be understanding the propagation.

\section{SUBJECT TERMS}

Infrasound, Yield

\section{SECURITY CLASSIFICATION OF:}

a. REPORT

UNCLASSIFIED b. ABSTRACT

UNCLASSIFIED c. THIS PAGE

UNCLASSIFIED

17. LIMITATION
OF ABSTRACT
एा1 QOP LMG

19a. NAME OF RESPONSIBLE PERSON Robert Raistrick 19b. TELEPHONE NUMBER (include area 28 code) 
This page is intentionally left blank.

Approved for public release; distribution is unlimited. 


\section{Table of Contents}

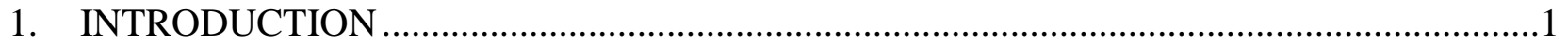

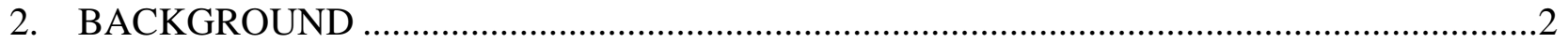

3. METHODS, ASSUMPTIONS, AND PROCEDURES .......................................................

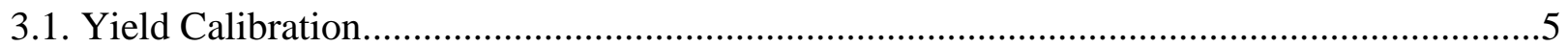

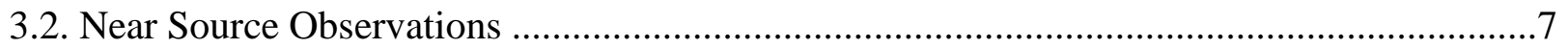

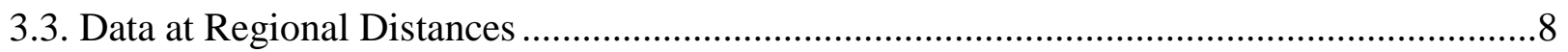

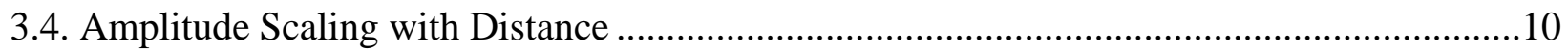

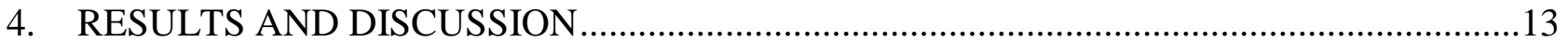

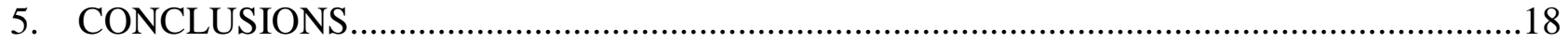

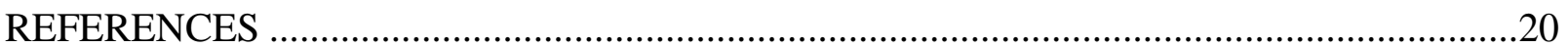




\section{List of Figures}

1. Location of NVAR and the Ammunition Disposal Site (New Bomb) ………..............................2

2. Effect of Weather on Acoustic Recordings at $1 \mathrm{~km}$ from the Source (Courtesy Robert Reinke, DTRA)

3. Median Correlation Coefficients for Same Pit, Nearest Pit, Next Nearest Pit and Two Seismic Signals (Upper Plot) and Actual Correlation Functions (Lower Plot)..........................................6

4. Seismic/Weight Relationship for New Bomb Events .............................................................

5. Amplitude/Weight, Period/Weight and Integral of the Pulse/Weight for a Near Source Data Set

6. Celerities of All Arrivals Observed During June 2009 - December 2011 Period. at DNIAR We Do Not Separate Between the Thermospheric and Stratospheric Arrivals

7. Example of a PSD curve for a FNIAR arrival .10

8. Effective Sound Speed and Corresponding Rays for a Line of Sensors Deployed North of the New Bomb Site to $176 \mathrm{Km}$ for the Days in Which Atmospheric Data Was Collected at Higher Altitudes.

9. Amplitude Versus Range for 3809 lbs of Mixed Ordnance for the Days in Which Tropospheric Arrivals Were Observed

10. Dominant Periods/Weight for New Bomb and UTTR Detonations. We Also Show the 1963 Relationship Which Appears to Scale the Data Up to 2,000 Lbs.

11. Dominant Period and Corner Frequency for New Bomb Observations at DNIAR and FNIAR.15

12. Yield Normalized Pressure Amplitudes Against Wind Parameters .16

13. Wind Corrected Amplitude Versus Range Observations and Best Fit. Also Shown Are the Estimates Using Different Formulas

14. BOOM Performance for New Bomb Observations 


\section{INTRODUCTION}

The Nevada Seismic Array (NVAR) was installed by Southern Methodist University (SMU) in December 1998, near the village of Mina, NV. The array is composed of 10 short period seismic elements with an aperture of $4 \mathrm{~km}$. Collocated with the central four seismic elements (NV01 to NV04) is an infrasound array (NVIAR), initially installed and operated under a University supported research program. NVIAR began operations at the same time as the seismic array. After the installation signals from an army munitions disposal facility were recorded. Figure 1 shows the approximate location of the array and detonation site (dubbed "New Bomb"), located approximately $36 \mathrm{~km}$ from NVIAR, and a typical seismo-acoustic observation at NVIAR. The recorded signals are represented by a suite of several explosions up to 4,000 lbs. TNT equivalent, spaced at an irregular interval ranging from 30 seconds to more than a minute apart. This pattern of multiple shots eases the detection problem considerably at greater ranges. Cooperation with the officials in charge of detonation is excellent. They have released yield, videotapes and exact GPS location of the disposal pits. Detonations take place continuously throughout the year, though there are periods of breaks particularly in winter, due to difficult weather conditions.

Because of the existence of the seismic array in the vicinity we were able to determine very accurate origin times of the detonations within a fraction of a second from calibrated seismic travel time. The seismic travel time was calibrated against GPS synchronized video recordings of the detonations. This allows us to calculate very accurate infrasound travel time. This research primarily used this source, extremely well calibrated, to address the issue of infrasound scaling relationships. We then extended the study to other sources including infrasound signals from single fired explosions detonated at the Utah Test and Training Range. This source provided the upper limit of yield in the scaling relationship (up to 60 tons TNT equivalent). 


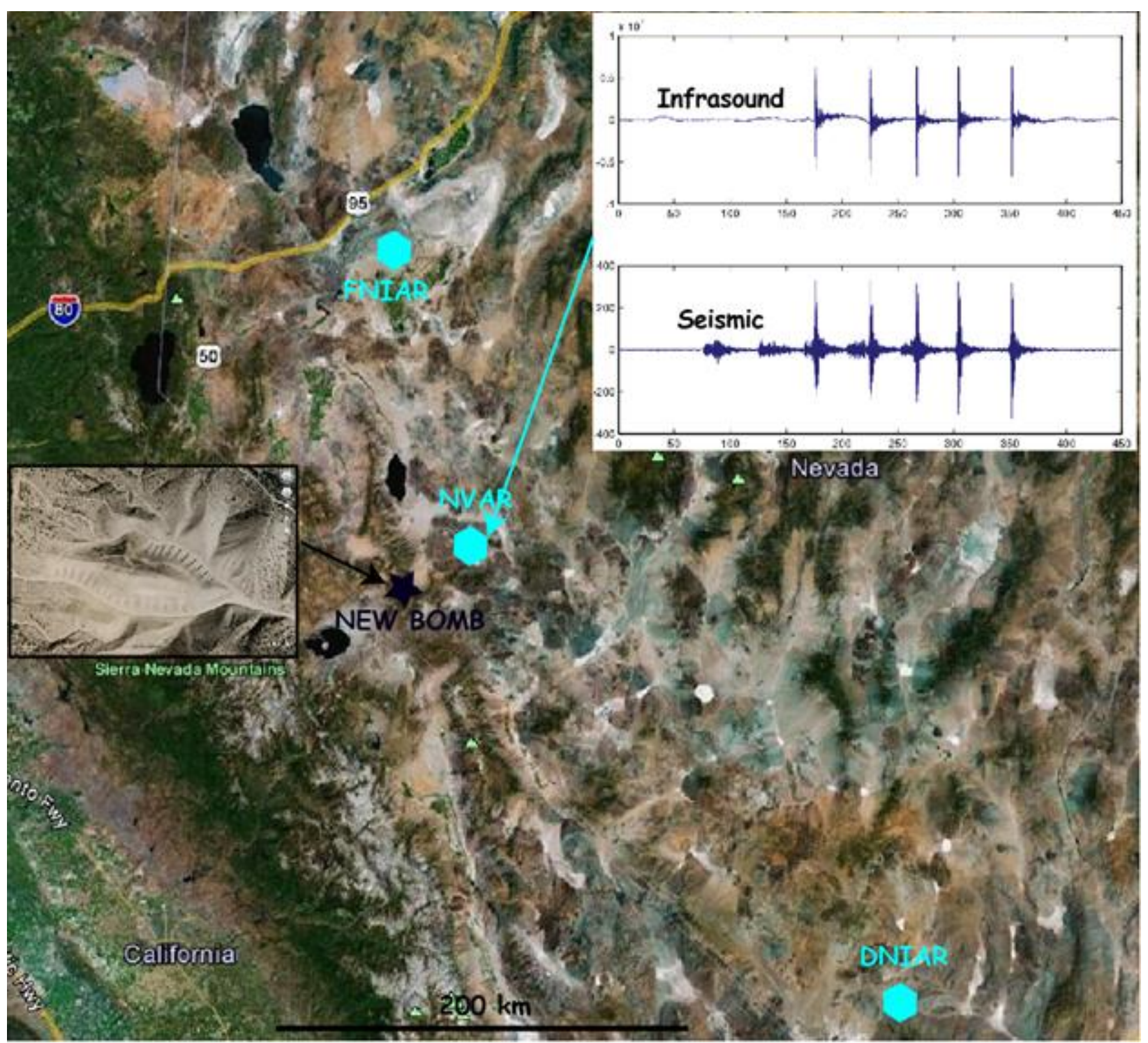

Figure 1. Location of NVAR and the Ammunition Disposal Site (New Bomb)

Shown in medallions, in Figure 1, are a typical observation of seismic and infrasound observations at NVAR and the plan layout for the disposal pits. Also shown are the locations of FNIAR and DNIAR, where the bulk of our data was recorded.

\section{BACKGROUND}

The yield estimation problem is more complicated in infrasound than seismic because the atmospheric effects are more difficult to quantify. Though there have been several relationships developed, the uncertainty in the yield estimates vary from at least a factor of two to more than one order of magnitude. 
The yield of an explosion has been historically estimated from the dominant period of the observed signal or from (often wind corrected) pressure amplitude. Two source scaling relationships are in use for near source observations, and they were developed mostly for blast mitigation. The American National Standards Institute (ANSI) [1] relationship uses a cube root decay of the pressure pulse with distance for close in observations, while at greater distances (beyond $10 \mathrm{~km}$ ) the inferred exponent is 1.1. Exactly where the transitions from near field to far field for different source sizes occur is explained rather loosely in terms of wavelength or wavefront geometry.

In addition atmospheric effects (e.g., wind, temperature) have an effect on acoustic amplitudes and periods, however, the distances/pressures at which the temporal variability of the propagation medium begins enhancing/destroying acoustic signals is not well established. It is also unknown if these effects can be corrected for consistently, especially when atmospheric data are limited. Figure 2 shows the amplitudes of near source $\mathrm{N}$-waves from one of the HUMBLE REDWOOD explosions [2] at Kirtland AFB near Albuquerque, NM. Though all the stations were located at $1 \mathrm{~km}$ from the source there is a factor of two variations in the zero to peak amplitudes of the $\mathrm{N}$-waves. Also it is interesting to note that the variations in period are much smaller

The second near field source scaling relationship is the Blast Operational Overpressure Model (BOOM) [3], which introduces an empirical parameter to correct for the potential bias introduced by weather. The Beta parameter takes into account the source/receiver distance, the effective sound speed at the surface and a relationship between the maximum change in the effective sound speed and the altitude at which the maximum effective sound speed is observed. The applicability of BOOM and ANSI relationships is usually reduced to less than $50 \mathrm{~km}$, and the observed infrasound would be tropospheric.

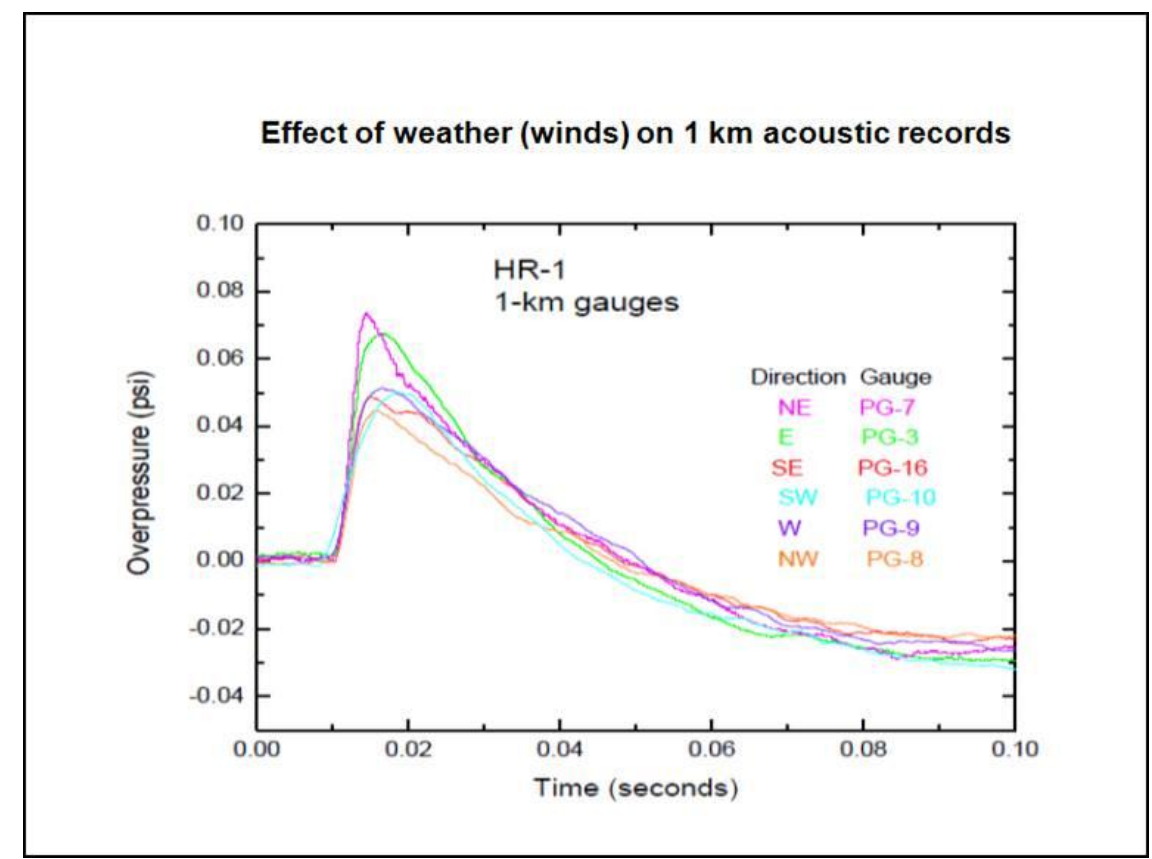

Figure 2. Effect of Weather on Acoustic Recordings at $1 \mathrm{~km}$ from the Source (Courtesy Robert Reinke, DTRA) 
The problem is more complicated at low yields for long range propagation. Low yield explosions leads to higher frequency signals which are affected by finer scale atmospheric homogeneities. To correct for this would require atmospheric models with better vertical sampling than the current G2S models [4]. In addition we have observed that the characteristics of stratospheric arrivals can change on the order of less than 5 minutes much shorter than the six hour long average of the $\mathrm{G} 2 \mathrm{~S}$ models.

For long range propagation several scaling relationships were obtained from large chemical or nuclear explosions [5, 6, 7 (1964 AFTAC empirical formula, relationships used by Russian scientists)]. In a general form the formulas that use amplitudes can be written as:

$$
\log (P)=p+m \log (W)+n \log (R)
$$

Where $\mathrm{P}$ is zero to peak pressure in Pascals, $\mathrm{W}$ is yield in $\mathrm{Kt}$ and $\mathrm{R}$ is distance in $\mathrm{km}$ (though in the Pierce and Posey formula $R$ is replaced by $R \sin (\Delta)$ where $\Delta$ is the distance in degree) and $p$, $m$ and $n$ are constants. A similar formula was used by Russian scientists to calculate the yield of atmospheric nuclear explosions [8]. The yield exponent $m$ which shows how pressure decays with yield is the driving factor in estimating a detection threshold. It varies from value of 1 in the Pierce and Posey formula to 0.33 used by Russian scientists, while Clauter and Blandford and Whitaker formulas have intermediate exponents ( 0.5 and 0.68 , respectively). In an attempt to correct for the effects of the wind on the amplitude Whitaker [7] uses wind corrected amplitude. The correction is based on the stratospheric wind value at $50 \mathrm{~km}$ in the direction of propagation and is used to calculate a pressure value in a zero wind atmosphere. Such corrections are documented to be very large in extreme propagation conditions. In the Russian formula a different value of $\mathrm{q}$ is used for downwind or crosswind propagation in an attempt to correct for the wind bias. It should be noted that the Whitaker [7] formula was developed at a time when there were no detailed atmospheric models (such as G2S), though some rocket soundings were available. The altitude of $50 \mathrm{~km}$ was chosen based on the assumption that the signals were refracted at that altitude. This formula should be revisited for use with the current, more detailed models, and should use the altitude of the expected refracted signals (which is unlikely to be exactly $50 \mathrm{~km})$.

The AFTAC empirical formula makes use of the dominant period of the main acoustic signal (stratospheric) and the overall regression is about a factor of two. However, when the above formulas were tried for a dataset of Soviet nuclear explosions [8] the variations in the measured amplitudes were more than one order of magnitude for the same yield. It was also found that the cube root of yield scales with the observed periods (similar to the AFTAC formula), but for the Russian dataset it shows considerable scatter. This scatter and the smaller cube root exponent would lead to high uncertainty in any yield estimate based on measured period. However, there could be additional sources of errors in the methodology employed by Stevens et al. [8] (e.g., yield of explosions might not have been very well constrained, or all types of arrivals are taken into account).

To summarize this background paragraph we emphasize that no extensive work was carried out on low yield explosions at regional distances. The literature discussed above refers to either near source (shock waves to acoustic tropospheric arrivals) or large (nuclear mostly) explosions. 


\section{METHODS, ASSUMPTIONS, AND PROCEDURES}

\subsection{Yield Calibration}

The first step in yield studies is to determine how accurate our constraint on actual yields is. Several types of materials are usually disposed during normal operations in Hawthorne which complicates the determination of the actual yield of the detonation. The actual weight of the disposed material is carefully recorded in the archives of the ammunition depot, but same weights can actually have different yields depending on the explosivity of the chemical cocktail. Therefore we calibrated a weight/seismic amplitude relationship using the NVAR array. The only assumption that we make is that the mechanisms of energy partition in infrasound and seismic energy does not change with the seismic cocktail. A pilot study was carried out on a limited dataset to study the similarity of the seismic signals and the possibility of using the seismic observations as a measure of yield. For the regular shot pattern shown in figure 1 the first infrasound signal is observed during the arrival of the third seismic signal. In most cases the infrasound signals couples locally into Rayleigh waves and contaminate the seismic signals. Therefore for yield information we can use only the seismic signals from the first two detonations. We have a selected a limited dataset of events and examined the maximum correlation coefficients of the first two signals from a set of detonations occurring during a few months. For shots fired in the same pit the median correlation coefficients were very high, above 0.95 (Figure 3). For detonations fired in adjacent pits the median correlation coefficient dropped to 0.71 , while for shots fired in the next nearest pit the correlation coefficients dropped to 0.35, similar to the noise correlation values for the window length of interest (20 second window at 40 samples per second).

We have requested several detonation logs during the past field experiments. The selection of the logs was done based on the observations of seismic amplitudes at NV08 in the desire to have observations at all weights. Shown in figure 4 are the seismic RMS (root mean square) amplitude and weight relationships for the detonation logs available to us. The seismic measurements were taken for a 20 second long time window. We have selected channel 8 because is the only channel located within hard rocks, and it is not expected to exhibit amplitude variations. The smallest weights in the figure are $868 \mathrm{lbs}$, while the largest are a little below 4,000 lbs, but there are only few points between $868 \mathrm{lbs}$. and approximately 1,800 lbs. Explosions in this range are usually misfires and there is no weight information available. The error in the calibration relationship shown in figure 4 is about $10 \%$. 


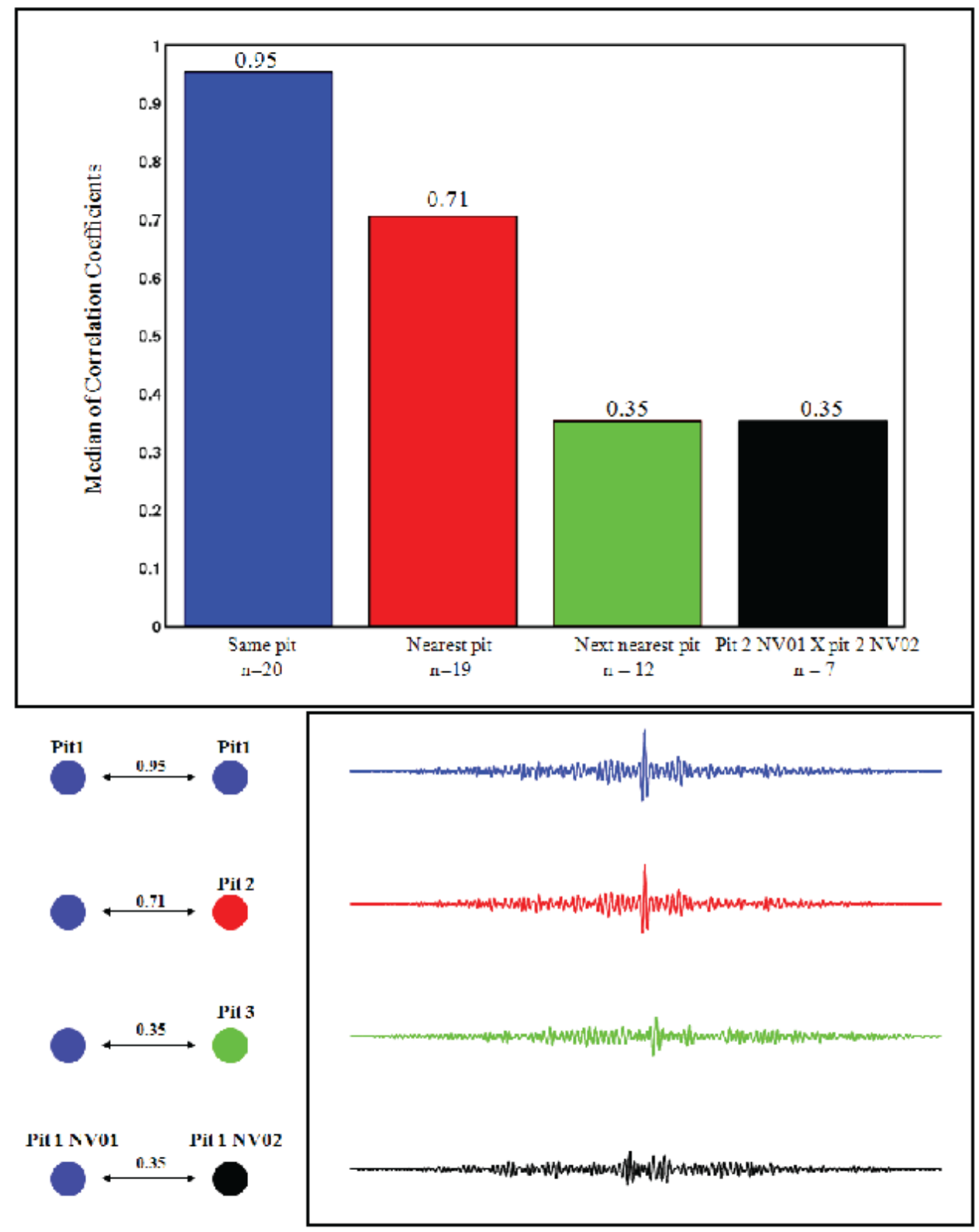

Figure 3. Median Correlation Coefficients for Same Pit, Nearest Pit, Next Nearest Pit and Two Seismic Signals (Upper Plot) and Actual Correlation Functions (Lower Plot) 


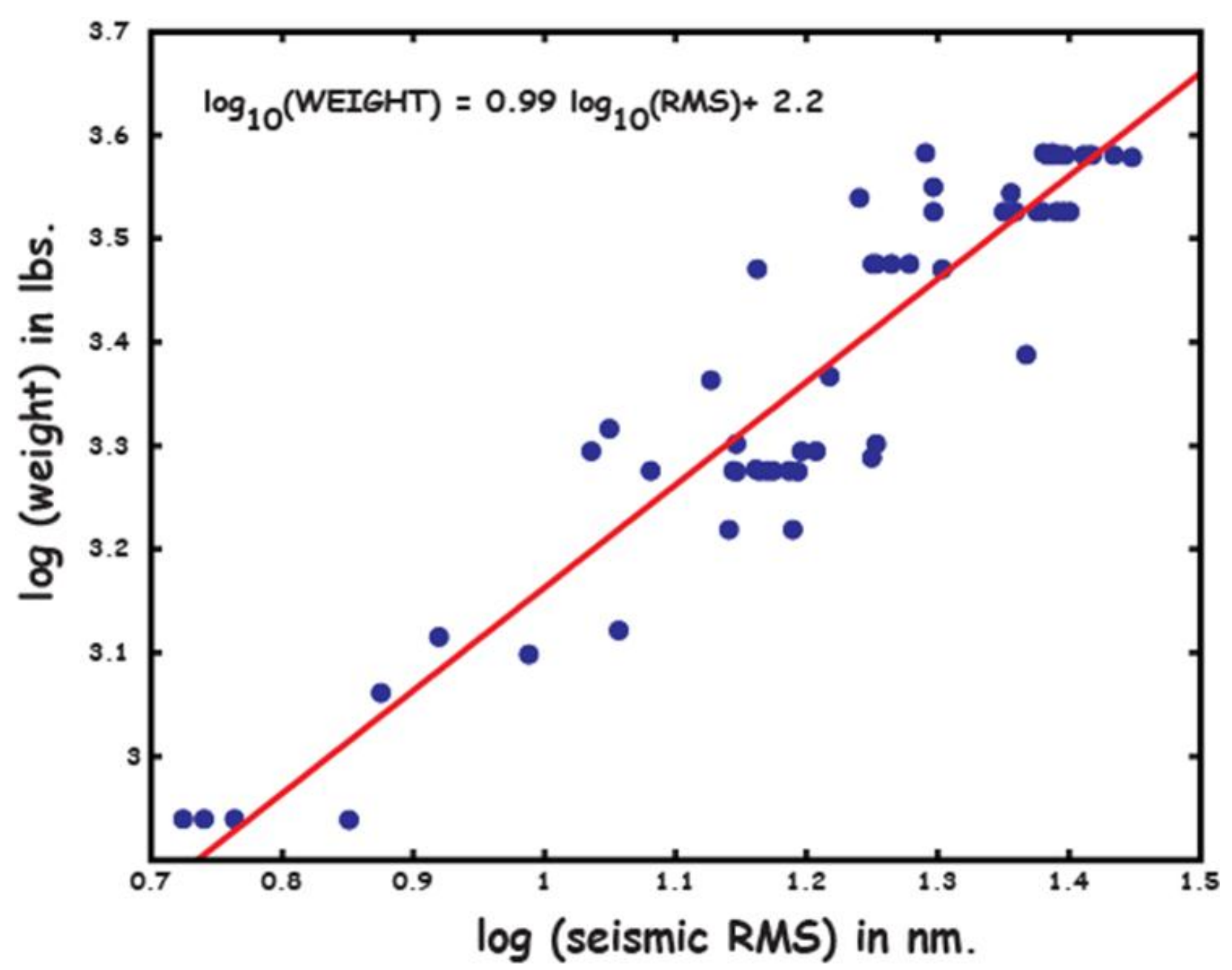

Figure 4. Seismic/Weight Relationship for New Bomb Events

\subsection{Near Source Observations}

Several datasets and sources were used in this study and we will discuss them below. The backbone of this study is focused on data acquired at two arrays located at regional distances. However, because of the difficulty in pinpointing a dominant period we have decided to acquire a dataset of near source observations. In the end a dataset with observations at ranges of 20 to $177 \mathrm{~km}$ will also be discussed.

The near source observations were acquired at distances ranging from $1.2 \mathrm{~km}$ (the furthest pit) to 800 meters (the nearest pit), and the waveforms are relatively similar to those shown in figure 2. The parameters measured were the peak amplitude, the period of the positive pulse from zero crossing and an integral over the pressure amplitudes for the period. Shown in figure 5 are the scaling relationships derived from these measurements, and the best fit. Out of the three of them the integral exhibits the lowest standard error of the estimate, while the peak amplitude is the poorest performer. 

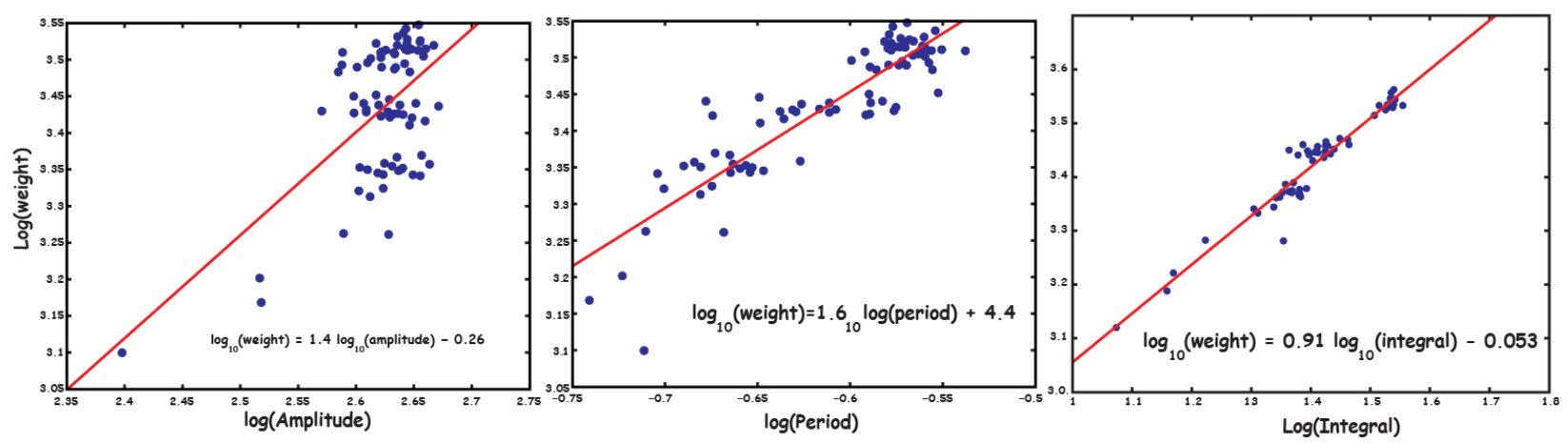

Figure 5. Amplitude/Weight, Period/Weight and Integral of the Pulse/Weight for a Near Source Data Set

\subsection{Data at Regional Distances}

In order to acquire a large dataset of infrasound observations from this ground truth source we have installed two research arrays at distances up to $300 \mathrm{~km}$ from the source. The first semipermanent array was installed in early June 2009. The array is located on the property of the Kennametal tungsten carbide plant a few km. north of Fallon, NV, at a distance of $154 \mathrm{~km}$ from the detonation site. The four element array, referred to as FNIAR, has an aperture of about 170 meters. At the end of October 2009 we have installed the second array (called DNIAR), located $293 \mathrm{~km}$ south east of the detonation site. Since June 2009 until December 2011 we have identified 378 arrivals (from 316 operating days) at FNIAR and 256 arrivals (from 239 operating days) at DNIAR.

As both the frequency and amplitude of the infrasonic arrivals are affected by transient propagation paths the first step is to sort the individual arrivals. Usually this is performed by examining the celerity (Figure 6), defined as source/receiver distance divided by the total travel time. At FNIAR 92\% of the detonations have stratospheric arrivals (celerities below $300 \mathrm{~m} / \mathrm{s}$ ), while only $27 \%$ of the detonations have tropospheric arrivals (celerities usually higher than 330 $\mathrm{m} / \mathrm{s}$ ). DNIAR exhibits strong seasonal variations, with the absence of stratospheric arrivals in summer and multiple arrivals in winter. Roughly the celerity limits at this array are: tropospheric higher than $330 \mathrm{~m} / \mathrm{s}$, stratospheric 320-280 m/s and thermospheric below $280 \mathrm{~m} / \mathrm{s}$, but there are cases in which we are not able to discriminate between these arrivals (during periods of wind turnover and January/February when stratospheric storms could occur). We have focused our study on the stratospheric arrivals, which are by far the most numerous. 

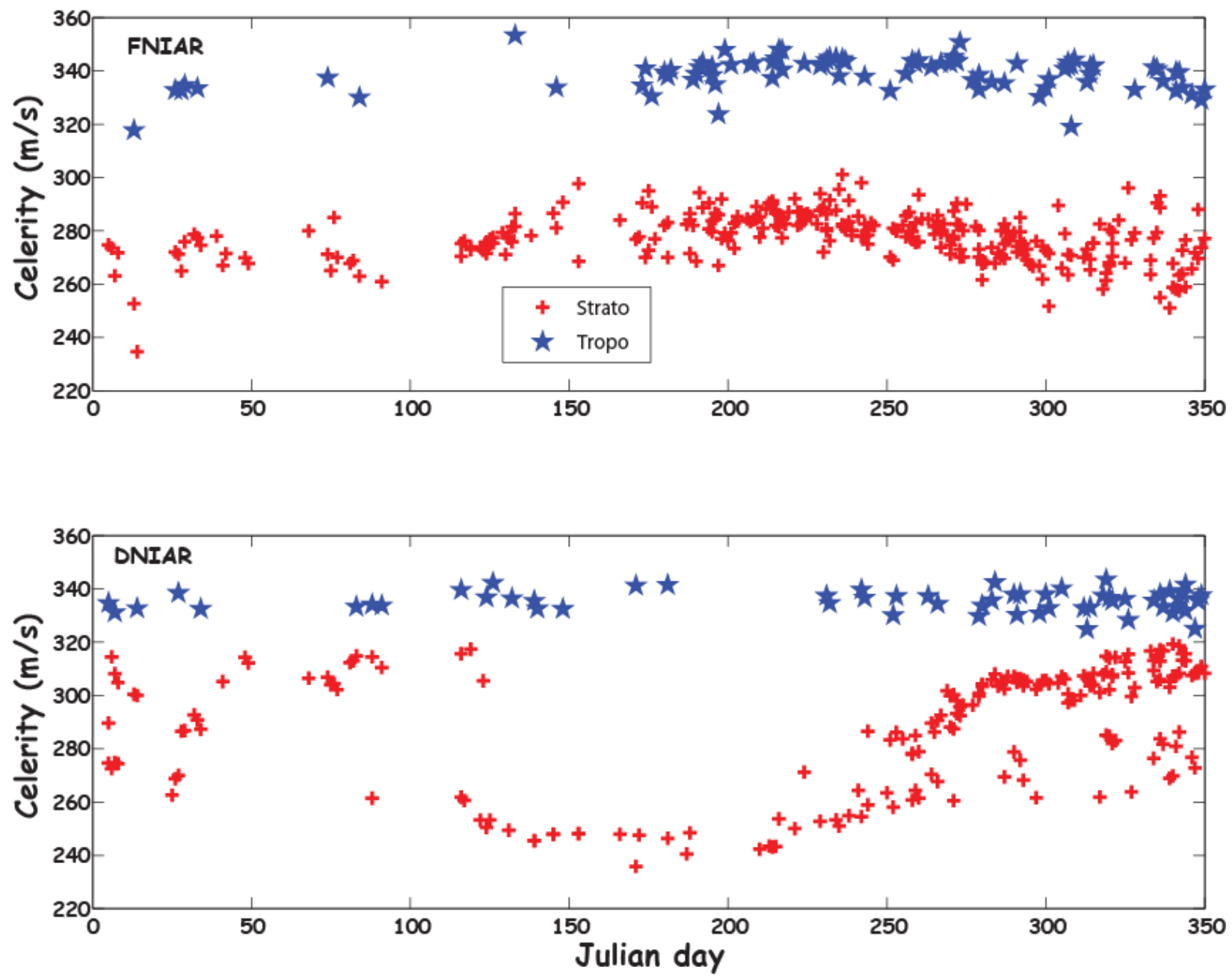

Figure 6. Celerities of All Arrivals Observed During June 2009 - December 2011 Period. at DNIAR We Do Not Separate Between the Thermospheric and Stratospheric Arrivals.

We have used a variety of methods in our attempt to determine the dominant period as accurately as possible. After filtering the data $\left(0.5-5 \mathrm{~Hz}\right.$ with a $2^{\text {nd }}$ order Butterworth filter) and correcting for the instrument response we have applied both an autoregressive technique and Fourier based methods to determine the dominant period. In the cases in which the signals had short duration resolution in the frequency domain was poor and we obtained good results using a low order AR technique (order 8). However, in the case of complex signals even high order AR techniques (order 48) did not provide a good representation of the spectrum. In general an AR techniques had comparable results with the Fourier based methods. To illustrate the difficulties of pinpointing the frequency of the arrivals we show in figure 7 the spectra of a signal observed at FNIAR. The spectra do not show a strong spectral peak but a suite of peaks of approximately equal energy level from 0.6 to $2.1 \mathrm{~Hz}$. The extreme values would translate in more than order of magnitude in yield estimates. In general half of the observed signals have dominant peaks, while about half of them have spectra similar to that shown in figure 7. 


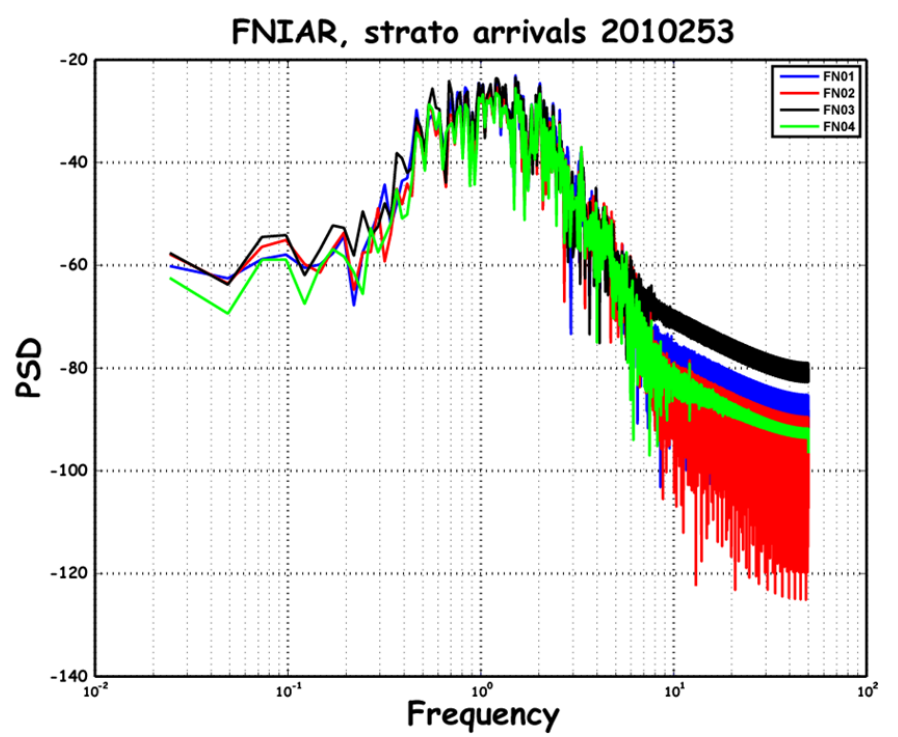

Figure 7. Example of a PSD curve for a FNIAR arrival

The observed UTTR arrivals have in general prominent peaks and determining the dominant period does not pose significant problems for UTTR signals. UTTR signals are usually represented by at least one stratospheric arrival (celerity near $300 \mathrm{~m} / \mathrm{s}$ ), though in most cases we also observe a second stratospheric arrival.

We have also analyzed the behavior of the peak amplitudes at FNIAR and DNIAR. The most common method to use amplitude for yield determination is to correct the raw amplitudes for the effect of the stratospheric wind. In general the wind in the direction of propagation at a height of $50 \mathrm{~km}$ is used. That height is chosen because the stratospheric signals are expected to return from around that altitude. However, when this correction was developed there were no detailed atmospheric models (such as G2S), and there is no reason to believe that the stratospheric arrivals are turning exactly at a height of $50 \mathrm{~km}$. Taking advantage of the detailed atmospheric profiles currently available we have attempted to develop empirical corrections to reduce the variance of the amplitude observations. First we have constructed effective sound speed profiles from G2S models, and then we calculated various wind parameters (the classic winds at $50 \mathrm{~km}$, maximum stratospheric winds, winds at the maximum effective sound speed and a mean wind value for the entire surface maximum effective sound speed normalized by the altitude where that value occurs).

\subsection{Amplitude Scaling with Distance}

Apart from the datasets discussed above which gave us a large number of observations at fixed distances, we will also discuss a dataset of observations at several multiple ranges. They were collected in June 2009 during a week-long (Julian days 173 to 177) field experiment in which single channel digitizers were deployed in a northerly direction at distances ranging from 2.5 to $176 \mathrm{~km}$ from the source. Atmospheric data was collected in the path of the propagating signals for all days of the experiment. However, due to a malfunction there is no atmospheric data higher than $5 \mathrm{~km}$ for the first day of the experiment (day 173). During the four days in which higher altitude atmospheric data was collected we had a great variability in the 
meteorological data. Figure 8 shows the effective sound speed profiles built from the actual meteorological measurements and the corresponding rays.

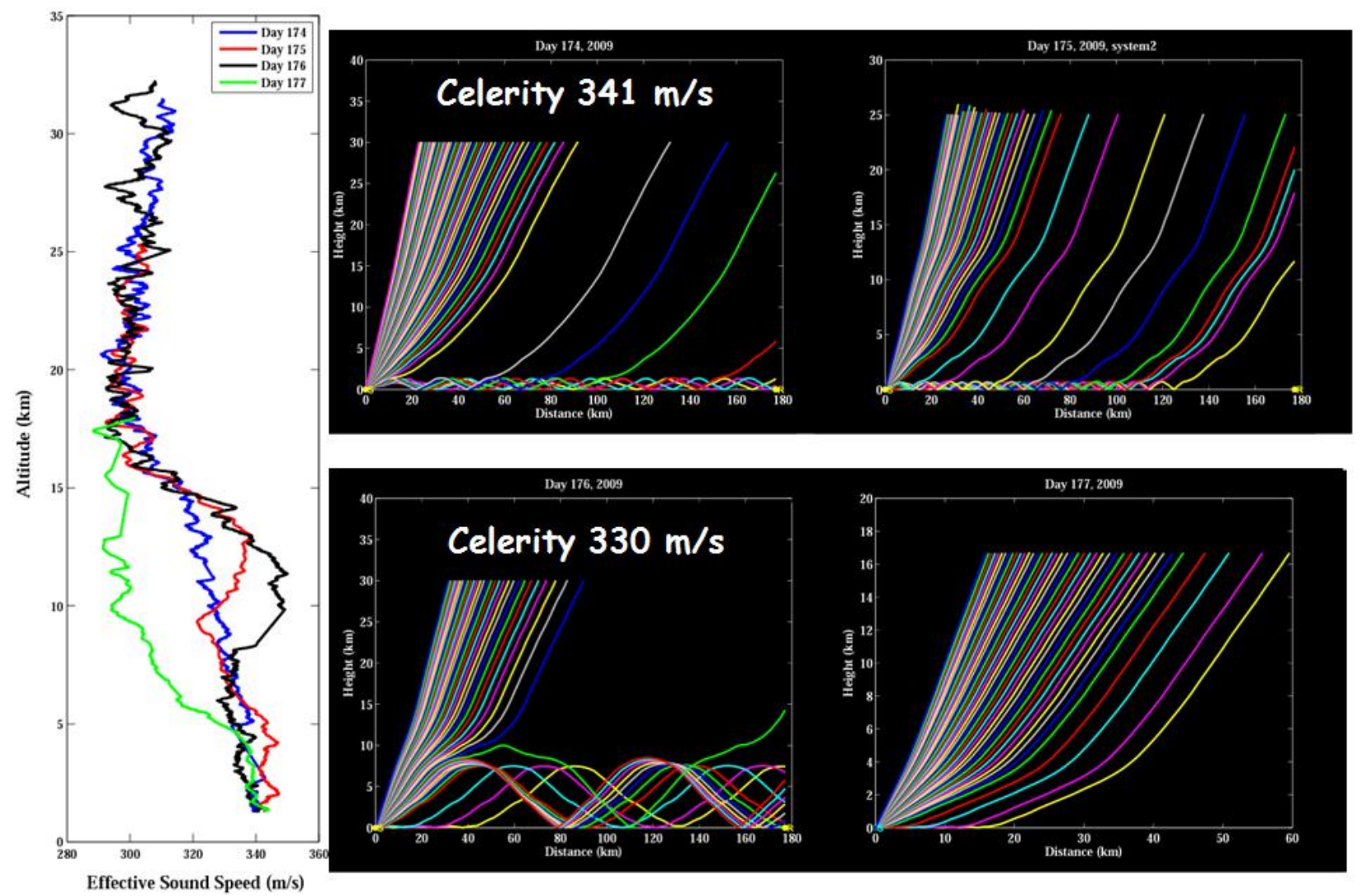

Figure 8. Effective Sound Speed and Corresponding Rays for a Line of Sensors Deployed North of the New Bomb Site to $176 \mathrm{Km}$ for the Days in Which Atmospheric Data Was Collected at Higher Altitudes.

The figure shows there is an inversion layer between 8 and $12 \mathrm{~km}$ we believe to be due to the jet stream during Julian day 176, while during days 174 and 175 raytracing suggests the observed arrivals propagated in near surface ducts. No stratospheric arrivals were observed except for the last day (day 177) and those occurred at distances over $154 \mathrm{~km}$. The atmospheric data collected for day 173 (not shown in figure 8) suggests the near surface atmospheric conditions are similar to day 174. Due to the proximity of the sensors to highways this dataset is relatively noisy and it was difficult to identify the actual arrivals at all stations. Figure 9 shows the observed amplitudes of the tropospheric arrivals (days 173 to 176) and the least square fit through the dataset. All the detonations were 3809 lbs. of mixed ordnance. What is interesting is that the amplitudes of all arrivals observed from the low altitude duct (days 173 to 175) decay in the same way, while the jet stream propagation (day 176) is affected by focusing and defocusing effects. 


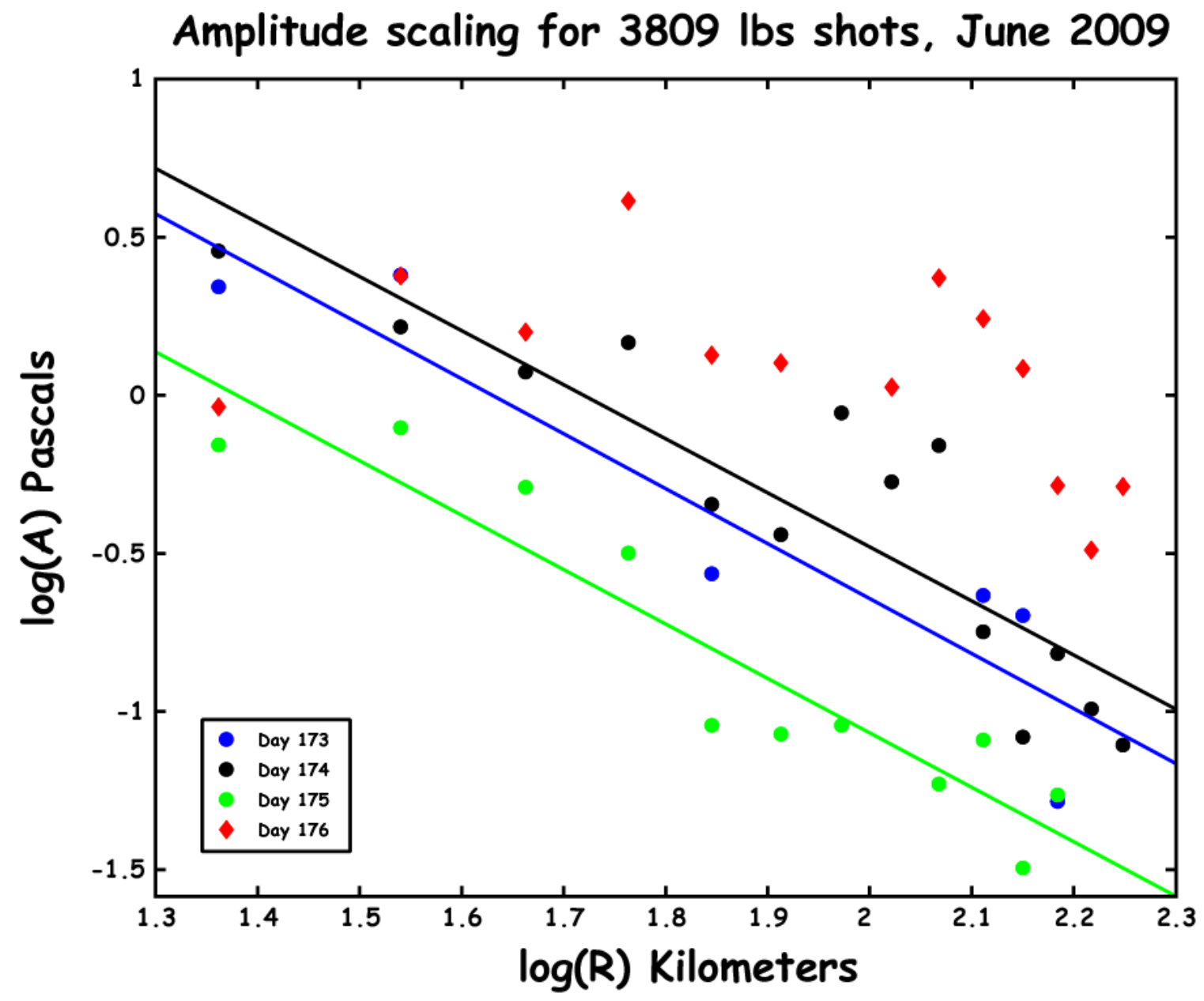

Figure 9. Amplitude Versus Range for 3809 lbs of Mixed Ordnance for the Days in Which Tropospheric Arrivals Were Observed

We have used several scaling relationships that were published in literature that we applied to our dataset. Some of them were summarized in a paper by Stevens et al 2002:

$$
\begin{aligned}
& \log (P)=-1.54+\log (W)-0.5 \log (R \sin \Delta), \text { Pierce and Posey } \\
& \log (P)=0.92+0.5 \log (W)-1.47 \log (\Delta), \text { Clauter and Blandford, } 1998 \\
& \log (P)=3.37+0.68 \log (W)-\log (R), \text { LANL formula } \\
& \log (P)=3.00+0.33 \log (W)-\log (R), \text { used by Russian scientists }
\end{aligned}
$$

Where $\mathrm{P}$ is the zero to peak pressure in Pascals, $\mathrm{W}$ is the yield in $\mathrm{kt}, \mathrm{R}$ is the distance in $\mathrm{km}$ and $\Delta$ is the distance in degrees.

All formulas were developed from datasets of nuclear explosions and therefore we applied a correction for the chemical energy release. Considering that a chemical explosion releases half of 
the energy released by a similar yield nuclear explosion we have applied the following correction:

$$
\log \left(P_{C}\right)=\log \left(P_{n}\right)-\log (2)
$$

Where Pc is the pressure observed from a chemical explosion and Pn is the pressure observed from a nuclear explosion. A wind correction is also applied. The role of the formula is to correct observed pressure to zero wind conditions. The correction is:

$$
\log \left(P_{\text {cor }}\right)=\log \left(P_{\text {raw }}\right)-0.018 V_{d}
$$

where $P_{\text {cor }}$ is the corrected zero to peak pressure amplitude, $P_{\text {raw }}$ and $V_{d}$ is the maximum wind in the propagation direction.

We have also used the Blast Operational Overpressure Model (BOOM) of Douglas 1987, to match our observations. The model is applied at distances of 5-50 km and is used to predict the amplitudes of the overpressure. The BOOM relationship is defined in term of a weather parameter B as follows:

$$
L=103.1+\frac{B}{5.3}+20 \log \left[\left(\frac{S}{1013}\right)^{0.556}\left(\frac{W}{110}\right)^{0.444}\left(\frac{25}{R}\right)^{1.393}\right]
$$

where

$$
B=\operatorname{arctangent}\left[3\left(\frac{\Delta V}{\Delta z}\right)\left(\frac{R}{c}\right)\right]
$$

The relationship is dependent on the parameter B (in degrees) which takes into account the atmospheric conditions at the time of the detonations. $\Delta \mathrm{V}(\mathrm{m} / \mathrm{s})$ is the maximum difference in the sound speed and the surface sound speed and $\Delta \mathrm{Z}(\mathrm{km})$ is the altitude at which $\Delta \mathrm{V}$ is observed, $\mathrm{C}$ is the sound speed at the surface (in $\mathrm{m} / \mathrm{s}$ ), $\mathrm{R}$ is the distance to location of interest $(\mathrm{km}), \mathrm{S}$ is the surface atmospheric pressure (mbar), $\mathrm{W}$ is TNT equivalent of explosive weight (in $\mathrm{kg}$ ) and $\mathrm{L}$ is the maximum overpressure expressed in $\mathrm{dB}$. The conversion factor from $\mathrm{dB}$ to Pascals is given by:

$$
P K=0.00002 * 10^{(L / 20)}
$$

where PK is the pressure expressed in Pascals.

\section{RESULTS AND DISCUSSION}

Figure 10 shows the dominant periods obtained for all UTTR and NEW BOMB stratospheric observations at FNIAR, DNIAR and NVIAR. Superimposed on the figure is the 1963 AFTAC empirical relationship developed from large nuclear explosions. This line is not a best fit for the data, but it appears to scale the dataset up to yields of 2,000 lbs. The most likely cause for this departure at low yields is a sampling issue (few datapoints below 2,000 lbs.) though it could also have a physical basis. In theory the lower the yield the shorter the periods, and we may actually observe an approach of the periods towards the origin. A more important issue is the range of the 
period determinations. The most difficult problem was to pinpoint the periods accurately, in particular for the NEW BOMB shots because propagation effects complicate the spectral contents. In general UTTR observations have clear spectral peaks, probably because interference is somewhat limited due to larger propagation distances, but even in this case, there is still quite a large variation. Given the high 3.34 exponent inferred from the AFTAC relationship a small error in the period determination translates in a large variance in the yield determination.

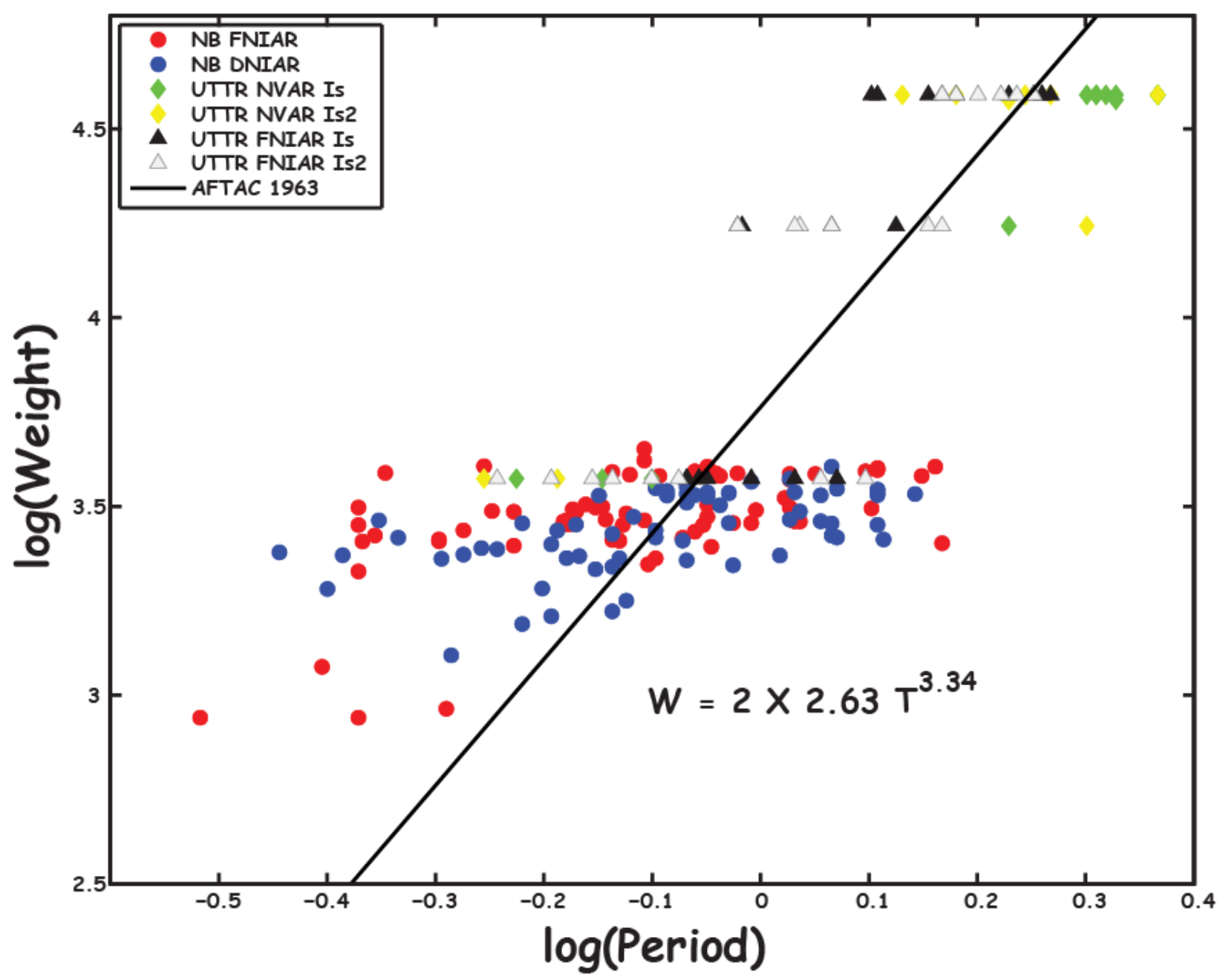

Figure 10. Dominant Periods/Weight for New Bomb and UTTR Detonations. We Also Show the 1963 Relationship Which Appears to Scale the Data Up to 2,000 Lbs.

In an attempt to reduce the variance of the period estimates we reanalyzed the New Bomb dataset with two approaches. One was to apply a suite of narrow band filters and determining the frequency at which the maximum power is observed, while the second approach was to track the changes in the corner frequency. In seismology the corner frequency is determined by fitting the observed spectrum with a Mueller - Murphy source model. However, in infrasound there is no equivalent Mueller - Murphy source model and a similar development of an infrasound source is very difficult because of the time variant atmosphere. Therefore we have to rely on direct observation of the cutoff frequency. An interesting observation is that about half of the signals exhibit a strong spectral peak while the other half shows a broad spectrum. This observation is 
valid for both FNIAR and DNIAR. Shown in figure 11 are the results according to their spectra. This figure yields an important observation regarding the frequency content of our signals. While the signals have similar dominant periods when a clear peak is present (similar least square coefficients for both DNIAR and FNAIR), DNIAR exhibits higher corner frequencies than FNIAR. This is remarkable because DNIAR is located at a greater distance than FNIAR, but it could be explained by differences in the propagation paths. Stratospheric signals at DNIAR are observed only in winter in very favorable stratospheric wind conditions, while the stratospheric winds on the path to FNIAR are in general much weaker. Also it should be noted that FNIAR is located in the middle of the shadow zone, and ray tracing do not predict the occurrence of the observed signals at FNIAR, therefore a different mechanism may be involved.

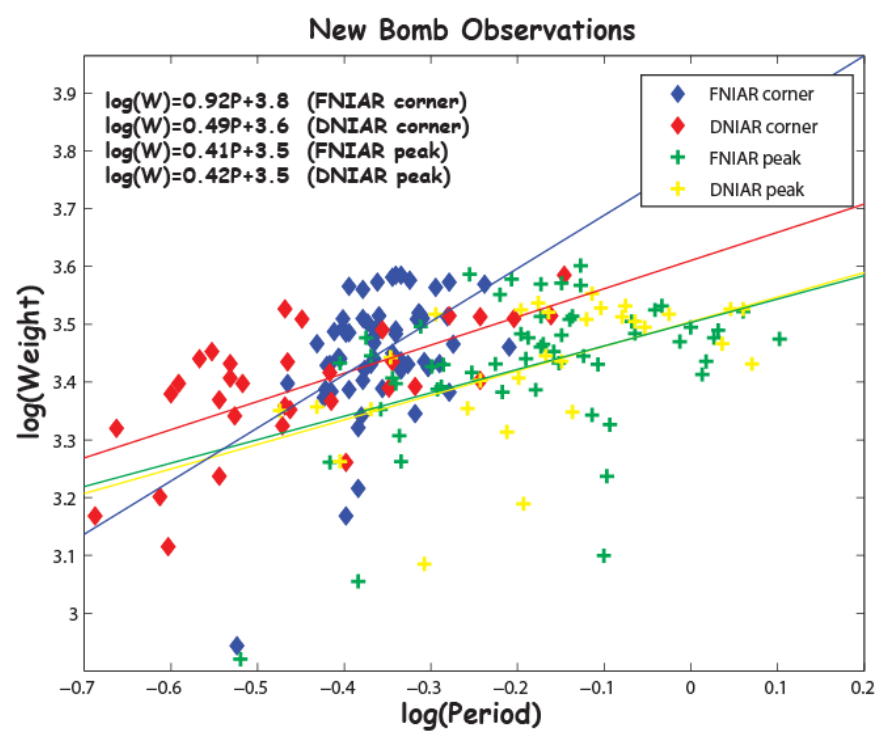

Figure 11. Dominant Period and Corner Frequency for New Bomb Observations at DNIAR and FNIAR

The most common method to use amplitude for yield determination is to correct the raw amplitudes for the effect of the stratospheric wind. In general it is used the wind in the direction of propagation at a height of $50 \mathrm{~km}$. The reason for choosing that height is that the stratospheric signals are expected to return from around that altitude. However, when this correction was developed there were no detailed atmospheric models (such as G2S), and there is no reason to believe that the stratospheric arrivals are turning exactly at a height of $50 \mathrm{~km}$. Taking advantage of the detailed atmospheric profiles currently available we have attempted to develop empirical corrections to reduce the variance of the amplitude observations. First we have constructed effective sound speed profiles from G2S models, and then we calculated various wind parameters. Shown in figure 12 is the amplitude scaled for yield plotted against two wind parameters. The first one is the wind at the maximum stratospheric effective sound speed, while the second one is an integral of the wind values up to maximum stratospheric effective sound speed normalized by the altitude where the maximum stratospheric wind is observed. Though the graph confirms our general knowledge of the wind patterns (stratospheric winds weakly favorable for FNIAR and most of the stratospheric observations at DNIAR are in favorable stratospheric wind conditions) there is more than one order of magnitude variance in the observed amplitudes (normalized for yield) for similar wind conditions. 


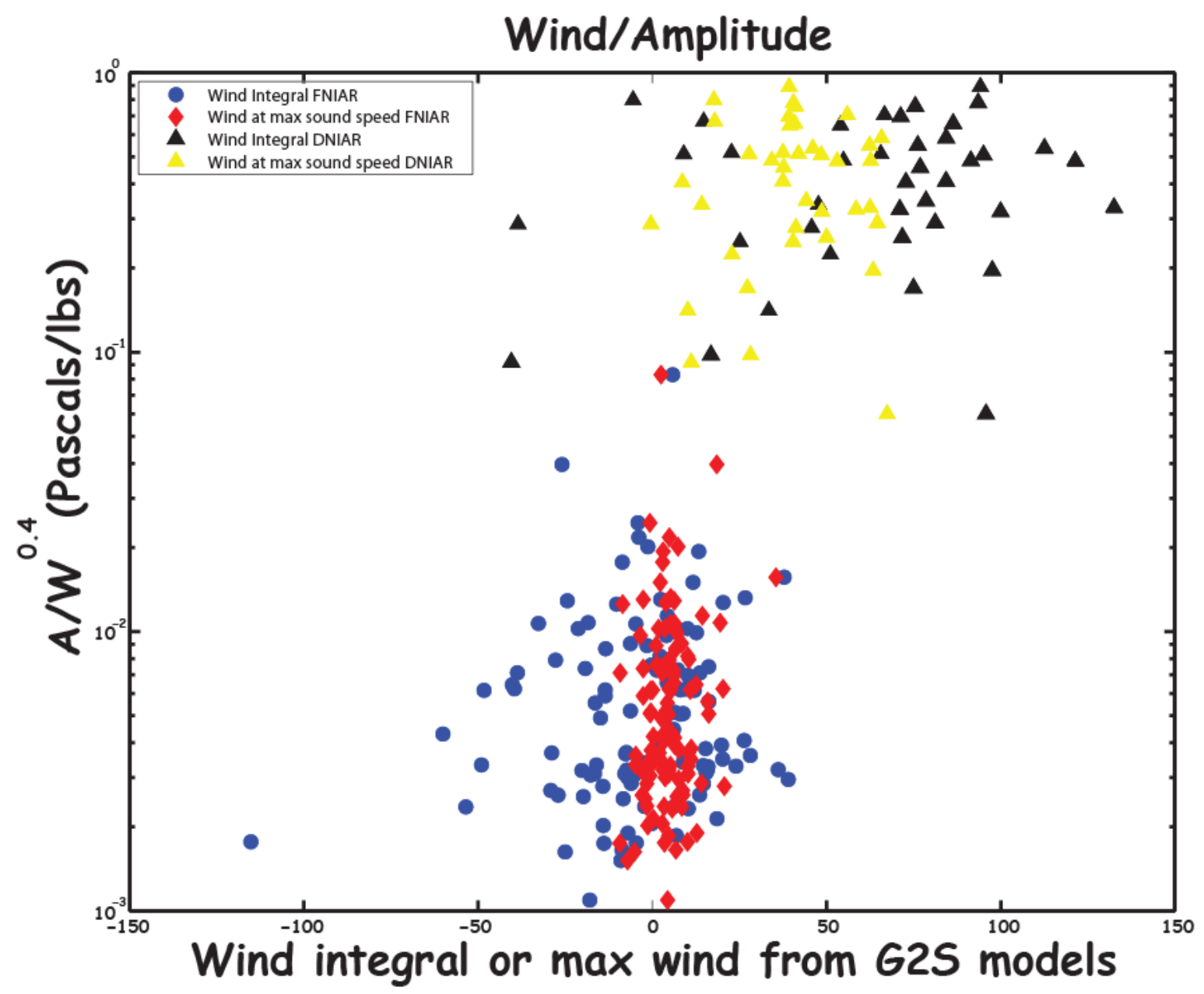

Figure 12. Yield Normalized Pressure Amplitudes Against Wind Parameters

The results for the dataset with observations at multiple ranges (2.5 $176 \mathrm{~km})$ are shown in figure 13. The best result is obtained by the Clauter and Blandford [6] formula, while Pierce and Posey [5] is completely off scale. Stevens et al [8] found that the Pierce and Posey formula, a theoretical derivation for the Lamb edge excitation fits relatively well with Lamb waves observed for very large nuclear explosions (yields larger than $1 \mathrm{Mt}$ ), but performed poorly for the rest of their dataset. The slope of the LANL formula is closer to the best-fit line as opposed to the formula used by Russian scientists, who consider the pressure to be proportional to the cube root of distance. The LANL formula was derived empirically on a dataset of stratospheric arrivals and makes use of wind corrected amplitudes, while our dataset is composed of only tropospheric arrivals.

However let's consider the general form of the ANSI relationship:

$$
A_{0}=C\left(\frac{R}{W^{m}}\right)^{p}
$$

where $\mathrm{A}_{0}$ is the amplitude, $\mathrm{W}$ is weight (or yield), $\mathrm{R}$ is the distance and $\mathrm{C}, \mathrm{p}$ and $\mathrm{m}$ are proportionality constants. If we take the logarithm of the above relationship any of the empirical 
or theoretical formulas discussed in the Methods section (apart from BOOM) can be obtained for a particular set of constants, therefore attempting to use the LANL formula at least for illustration purposes is appropriate.

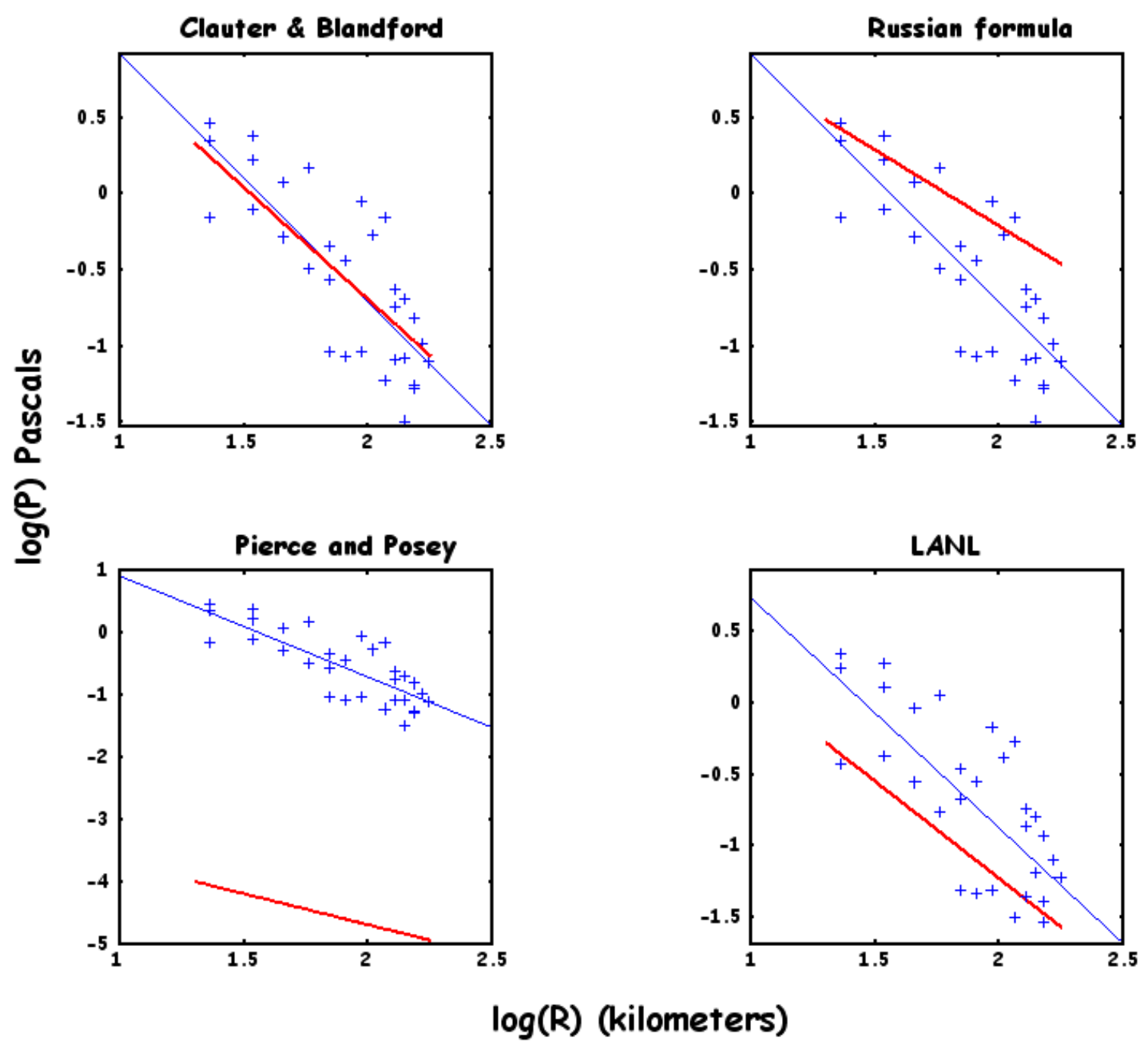

Figure 13. Wind Corrected Amplitude Versus Range Observations and Best Fit. Also Shown Are the Estimates Using Different Formulas 


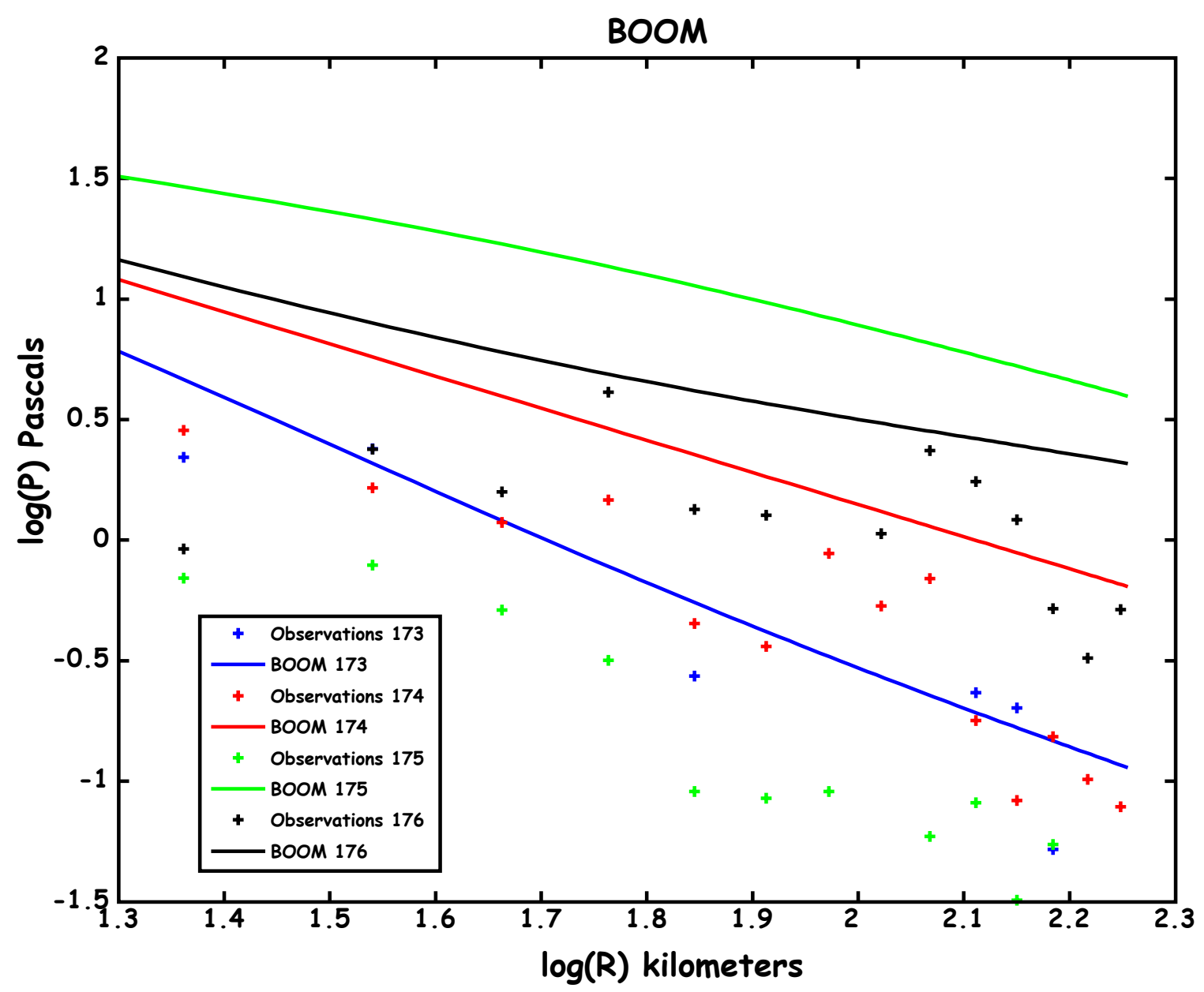

Figure 14. BOOM Performance for New Bomb Observations

The results for applying the BOOM model are shown in Figure 14. In this case we also show the values for day 176 as the B parameter takes the atmospheric conditions into account. For day 176 we used jetstream values for $\Delta \mathrm{V} / \Delta \mathrm{Z}$, while for the other days we used the maximum sound speed in the first few $\mathrm{km}$ of the troposphere. The difference between the results and the observations suggests that our knowledge of the actual meteorological conditions near the surface are not as well constrained as BOOM requires. This may be because the balloon launches were at the Hawthorne airport, about $35 \mathrm{~km}$ away from New Bomb and about $500 \mathrm{~m}$ difference in altitude between New Bomb and the airport.

\section{CONCLUSIONS}

It was difficult to estimate the dominant frequency of the arrivals and this resulted in a large variance of the period estimates, which would translate to about one order of magnitude variance for the yield estimates (Figure 10). A future direction of research would be devising methods to reduce the variance of the estimates. There are also notable differences between the signals observed at FNIAR and DNIAR which may point to a different propagation mechanism (perhaps scattering). The FNIAR arrivals are not predicted by classic raytracing methods and are usually lower amplitude and more complicated that those observed at DNIAR. Also there appears to be a 
lower frequency cut off than that observed at DNIAR. All those observations must be explained by the differences in the propagation paths, but the propagation path is poorly constrained at FNIAR. Currently the only way to predict these arrivals is to alter the effective sound speed profiles. Usually the effect of gravity waves is added to the effective sound speed profiles and this generates stratospheric inversions. There is definitely a need to better understand the propagation at this range to refine the yield estimates.

Also the frequency content of different types of arrivals is different, and therefore for monitoring purposes there should be a way to discriminate among the individual arrivals (among tropospheric, stratospheric and thermospheric). Currently there is no rigorous method apart from travel time, which is not always available. Amplitude variations of stratospheric arrivals at FNIAR and DNIAR are even more drastic, with more than one order of magnitude differences for similar wind conditions.

Tropospheric arrivals are more difficult to characterize because it requires knowledge of the atmosphere at a scale that is available only from radiosonde data. However, the amplitudes of the observed arrivals appear to attenuate with distance in the same way when the propagation mechanisms are similar (near surface propagation in our case). The slopes in Clauter and Blandford and Los Alamos formulas appear to match well the decay rate, but again there is more than one order of magnitude difference in the observed amplitude. This difference is usually reduced by applying wind corrections, but the existing methodology fails in this case. It appears therefore suitable to devise wind corrections that take into account more realistic models. 


\section{REFERENCES}

[1] Acoustical Society of America, American National Standard Estimating Airblast Characteristics for Single Point Explosions in Air, With a Guide to Evaluation of Atmospheric Propagation and Effects, Melville, NY: American Institute of Physics, 1983.

[2] Foxall, B., R. Marrs, E. Lenox, R. Reinke, D. Seastrand, J. Bonner, K. Mayeda, and C. Snelson, “The HUMBLE REDWOOD seismic/acoustic coupling experiments: Joint inversion for yield using seismic, acoustic, and crater data," Abs. Seism. Res. Letts., 81(2), 2010, p. 315.

[3] Douglas, D.A., (1987). Blast operational overpressure models (BOOM): an airblast prediction model, AFWL-TR-85-150, Kirtland AFB: Air Force Weapons Laboratory, April 1987.

[4] Drob, D. P. (2004). "Atmospheric specifications for infrasound calculations," Inframatics, 5, 2004, pp. 6-13.

[5] Pierce, A. and Posey, J., "Theory of the excitation and propagation of Lamb's atmospheric edge Mode from nuclear Explosions," Geophys. J. R. Astr. Soc., 26(1-4), 1971, pp. 341-368.

[6] Clauter, D. and Blandford, R., "Capability modeling of the proposed International Monitoring System 60-station Infrasonic Network," Proceedings of the Infrasound Workshop for CTBT Monitoring, Santa Fe, New Mexico, August 25-28, 1997, LANL report number LA-UR98-56, 1998.

[7] Whitaker, R., "Infrasonic monitoring," Proceedings of the $17^{\text {th }}$ Annual Seismic Research Symposium, Scottsdale, AZ, September 12-15, 1995, pp. 997-1000.

[8] Stevens J.L., I.I. Divinov, D.A. Adams, J.R. Murphy and V.N. Bourchik, “Constraints on infrasound scaling and attenuation relations from Soviet explosion data," Pure and Applied Geophysics, 159(5), 2002, pp. 1045-1062, DOI: 10.1007/s00024-002-8672-4. 


\section{DISTRIBUTION LIST}

DTIC/OCP

8725 John J. Kingman Rd, Suite 0944

Ft Belvoir, VA 22060-6218

1 cy

AFRL/RVIL

Kirtland AFB, NM 87117-5776 2 cys

Official Record Copy

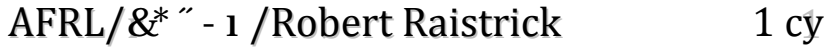


This page is intentionally left blank.

Approved for public release; distribution is unlimited. 